\title{
Antitumor Effects of Natural Compounds Derived from Allium sativum on Neuroblastoma: An Overview
}

\author{
Carlos César Patiño-Morales ${ }^{1,2} \mathbb{D}$, Ricardo Jaime-Cruz ${ }^{2}$, Concepción Sánchez-Gómez ${ }^{2}$, Juan Carlos Corona ${ }^{3} \mathbb{D}$, \\ Estefani Yaquelin Hernández-Cruz ${ }^{4}$ (D) Ivia Kalinova-Jelezova ${ }^{4}$, José Pedraza-Chaverri ${ }^{4}$, Perla D. Maldonado ${ }^{5}$, \\ Carlos Alfredo Silva-Islas ${ }^{5}$ and Marcela Salazar-García ${ }^{2, *}$
}

1 Laboratory of Cell Biology, Universidad Autónoma Metropolitana-Cuajimalpa, Mexico City 05348, Mexico; cpatino@cua.uam.mx

2 Laboratory of Developmental Biology and Experimental Teratogenesis, Hospital Infantil de México Federico Gómez, Mexico City 06720, Mexico; rjc@xanum.uam.mx (R.J.-C.); csanchez@himfg.edu.mx (C.S.-G.)

3 Laboratory of Neurosciences, Hospital Infantil de México Federico Gómez, Mexico City 06720, Mexico; jcorona@himfg.edu.mx

4 Department of Biology, Faculty of Chemistry, Universidad Nacional Autónoma de México, Mexico City 04510, Mexico; estefani.hernandez@quimica.unam.mx (E.Y.H.-C.); iviakj@comunidad.unam.mx (I.K.-J.); pedraza@unam.mx (J.P.-C.)

5 Laboratory of Cerebral Vascular Pathology, Instituto Nacional de Neurología y Neurocirugía Manuel Velasco Suárez, Mexico City 14269, Mexico; maldonado.perla@quimica.unam.mx (P.D.M.); csilva@innn.edu.mx (C.A.S.-I.)

* Correspondence: msalazar@himfg.edu.mx

Citation: Patiño-Morales, C.C.; Jaime-Cruz, R.; Sánchez-Gómez, C.; Corona, J.C.; Hernández-Cruz, E.Y.; Kalinova-Jelezova, I.; Pedraza-Chaverri, J.; Maldonado, P.D.; Silva-Islas, C.A.; Salazar-García, M. Antitumor Effects of Natural Compounds Derived from Allium sativum on Neuroblastoma: An Overview. Antioxidants 2021, 11, 48 https://doi.org/10.3390/ antiox11010048

Academic Editor: Domenico Nuzzo

Received: 16 November 2021

Accepted: 11 December 2021

Published: 27 December 2021

Publisher's Note: MDPI stays neutral with regard to jurisdictional claims in published maps and institutional affiliations.

Copyright: (c) 2021 by the authors. Licensee MDPI, Basel, Switzerland. This article is an open access article distributed under the terms and conditions of the Creative Commons Attribution (CC BY) license (https:// creativecommons.org/licenses/by/ $4.0 /)$.

\begin{abstract}
Garlic (Allium sativum) has been used in alternative medicine to treat several diseases, such as cardiovascular and neurodegenerative diseases, cancer, and hepatic diseases. Several publications have highlighted other features of garlic, including its antibacterial, antioxidative, antihypertensive, and antithrombotic properties. The properties of garlic result from the combination of natural compounds that act synergistically and cause different effects. Some garlic-derived compounds have been studied for the treatment of several types of cancer; however, reports on the effects of garlic on neuroblastoma are scarce. Neuroblastoma is a prevalent childhood tumor for which the search for therapeutic alternatives to improve treatment without affecting the patients' quality of life continues. Garlic-derived compounds hold potential for the treatment of this type of cancer. A review of articles published to date on some garlic compounds and their effect on neuroblastoma was undertaken to comprehend the possible therapeutic role of these compounds. This review aimed to analyze the impact of some garlic compounds on cells derived from neuroblastoma.
\end{abstract}

Keywords: neuroblastoma; garlic; S-allylcysteine; organosulfur compounds

\section{Neuroblastoma}

Neuroblastoma (NB) is a tumor derived from neural crest tissue. NB develops from sympathetic nervous system cells, specifically from sympathoadrenal progenitor cells [1]. Tumors appear mainly on the suprarenal medulla; signs and clinical symptoms can range from benign tumors to severe cases due to tumor metastasis. Over 650 patients are diagnosed in the United States every year, with a prevalence of 1 case per 7000 live births and an incidence of approximately 10.54 cases per million per year in children under 15 years of age [2,3]. NB prognosis is based on the extent of tumor differentiation, the presence or absence of stroma, the age of the patient, and the status of the MYCN oncogene and chromosome 11q.21,22. The patients are classified into four groups: (I) very low risk, (II) low risk, (III) intermediate risk, and (IV) high risk [4,5]. In 90\% of cases, low-risk patients have a favorable prognosis, whereas $60 \%$ of the high-risk patients have an unfavorable prognosis [6]. Moreover, treatment responses range from total remission to multiple drug resistance and severe toxicity [7,8]. It has been reported that half of patients with high-risk 
NB do not respond to first-line treatment or face relapse within the 2 years following the treatment [9-11].

NB is a heterogeneous disease from biological, clinical, morphological, and genetic perspectives, which poses a challenge for developing a universal treatment [12].

In this context, it is imperative to identify new therapies for childhood cancer that are affordable for the entire population and do not affect the patient's quality of life. Garlic compounds have therapeutic uses, and their study raises the possibility of their use as adjuvants in traditional NB treatment. Table 1 summarizes the studies that describe the effect of garlic-derived compounds on NB. Although there are studies on the antitumor effect of some garlic compounds on different types of cancer, more studies are required to describe the molecular mechanism involved in the antitumor effect on NB.

Table 1. Effect of aged garlic extract (AGE) and garlic compounds on neuroblastoma.

\begin{tabular}{|c|c|c|c|}
\hline Compound Used & Experimental Model & Main Findings & Reference \\
\hline Allicin & $\begin{array}{l}\text { SK-NFI, SK-N-AS, SK-N-Be, } \\
\text { and Kelly cell lines }\end{array}$ & $\begin{array}{l}\text { Induction of programmed cell death by the increase of poly } \\
\text { (ADP-ribose) polymerase (PARP). }\end{array}$ & [13] \\
\hline Allicin & SK-N-SH cell line & $\begin{array}{c}\text { Induction of apoptosis by activating the p38 MAPK } \\
\text { pathway and the release of cytochrome c. }\end{array}$ & [14] \\
\hline Allicin & BALB/c-nu/nu mice & $\begin{array}{l}\text { Tumour cell proliferation decreased; increase the number of } \\
\text { CD4+, CD8+, and NK cells and IFN- } \gamma \text { levels in the serum; } \\
\text { and decrease in mRNA and protein levels of VEGF. }\end{array}$ & [15] \\
\hline Z-ajoene & SK-N-AS cell line & Increase active caspase- 3 and p53. & [16] \\
\hline SAC & LA-N-5 human NB cell line & Decrease cell proliferation. & [17] \\
\hline SAC & SJ-NK-P and IMR5 cell lines & Induction of apoptosis and cell cycle arrest in the G1 phase. & [18] \\
\hline AGE & SJ-NK-P and IMR5 cell lines & $\begin{array}{l}\text { Decrease the mitochondrial membrane potential and } \\
\text { increased glutathione oxidation. }\end{array}$ & [18] \\
\hline DADS & SH-SY5Y cell line & $\begin{array}{l}\text { Release of cytochrome c, and activation of caspase-9 in } \\
\text { association with the activation of the JNK/c-Jun pathway. }\end{array}$ & [19] \\
\hline DAS and DADS & SH-SY5Y cell line & $\begin{array}{l}\text { Both compounds increase the intracellular } \mathrm{Ca}^{2+} \text { and induce } \\
\text { cell death through the release of cytochrome c. }\end{array}$ & [20] \\
\hline DADS & SH-SY5Y cell line & $\begin{array}{l}\text { Disruption of the cytoskeleton by Tau } \\
\text { protein dephosphorylation. }\end{array}$ & [21] \\
\hline DADS & SH-SY5Y cell line & Activation of PGC1 $\alpha$. & [22] \\
\hline DATS & $\begin{array}{l}\text { U87MG and } \\
\text { SH-SY5Y cell line }\end{array}$ & $\begin{array}{l}\text { Decrease of Bcl-2, and increased hydrogen sulfide } \\
\text { production and ROS production. }\end{array}$ & [23] \\
\hline
\end{tabular}

AGE: Aged garlic extract; DADS: diallyl disulphide; DAS: diallyl sulphide; DATS: diallyl trisulfide; IFN- $\gamma$ : Interferon- $\gamma$; JNK/c-Jun: c-Jun NH2-N-terminal kinase; NK: Natural killers; PGC1 $\alpha$ : peroxisome proliferator-activated receptor-Gamma co-activator 1 alpha; ROS: reactive oxygen species; SAC: S-allylcysteine; VEGF: vascular endothelial growth factor.

\section{Garlic}

Garlic (Allium sativum) is a bulb belonging to the family Liliaceae, which comprises approximately 600 species. Although garlic originated in Asia, it is now distributed worldwide. Anatomically, garlic consists of a bulb, commonly known as the head of garlic, which is divided into small bulbs known as garlic cloves [24].

Garlic has been used therapeutically since ancient times. Egyptian crypts contain the oldest visible inscriptions regarding the existence of garlic. The Ebers papyrus mentioned that garlic was used to treat over 30 diseases $[25,26]$. According to numerous studies, garlic is an effective drug in the prevention and treatment of several diseases, such as atherosclerosis, owing to its lipid-lowering effect, moderate decrease in arterial pressure, and fibrinolytic and platelet anti-aggregation activities. Garlic also possesses antioxidant, hypotensive, antimicrobial, antifungal, antitumorigenic, and immunomodulatory properties [27-31]. Among the numerous compounds in garlic, organosulfur compounds are of 
particular importance. In intact bulbs, the main component is alliin, but compounds such as S-glutathione, $\gamma$-glutamyl-S-allyl-cysteine, and $\gamma$-glutamyl-S-allylmercapto-L-cysteine can also be found. When garlic is cut, crushed, or ground, the enzyme alliinase catalyzes the formation of allicin from alliin. Approximately $1 \mathrm{mg}$ of alliin corresponds to $0.45 \mathrm{mg}$ of allicin. In addition to organosulfur compounds, garlic bulbs contain mineral salts (selenium, phosphorus, copper, and potassium), sugars, lipids, essential amino acids, saponins, terpenes, vitamins, enzymes, flavonoids, and other phenolic compounds [32].

An antioxidant activity has been reported for all garlic compounds, with S-allylcysteine (SAC) and allicin showing the highest activity. These compounds effectively inhibit free radical formation, enhance the endogenous radical scavenging mechanism, and increase the cellular antioxidant enzymes [33]. The antioxidant properties of garlic and its compounds are of great interest in relation to their anti-atherogenic, anti-hepatotoxic, and anti-cancer effects. However, the effects of garlic compounds on human health may occur in addition to their antioxidant properties. Garlic and its different commercial preparations are the most widely studied herbal supplements. Furthermore, the use of garlic constitutes the second most common complementary therapy, as it has been employed to reduce hypercholesterolemia and hypertension. In addition, hepatoprotective and neuroprotective properties have been attributed to garlic [34,35].

\section{Types of Garlic Preparations}

Garlic-based products are popular among the various dietary supplements available in the market. Garlic and its compounds are sold in several presentations [36].

Garlic oil: This presentation is rich in diallyl disulfide (DADS) and diallyl trisulfide (DATS). [37]. Garlic oil maceration: This presentation is rich in compounds such as vinyldithiin, ajoene, and other organosulfur compounds; it also contains residual amounts of alliin [38]. Garlic powder: The main organosulfur compound in raw and powdered garlic is alliin [39,40]. Aged garlic extract (AGE): This presentation has an increase in the amount of SAC, which becomes the main AGE compound. SAC is a stable water-soluble compound with a high bioavailability and high antioxidant properties [41].

The beneficial effects of garlic are attributed to the presence of organosulfur compounds (Figure 1), which represent approximately $1 \%$ dry weight; among these compounds, alliin is the most abundant [42,43]. Several epidemiological studies have suggested that eating garlic reduces the risk of certain types of cancer, including gastrointestinal cancer $[44,45]$. Studies on animals have provided evidence that garlic and its compounds inhibit carcinogenesis through some events, including the induction of apoptosis, inhibition of cell proliferation, scavenging of reactive oxygen species (ROS), increasing the activity of enzymes such as glutathione-S-transferase, and reducing the tumor size [46]. The effects of garlic-derived compounds on different types of cancer have been investigated; however, studies on their antitumor effects on NB are scarce. 


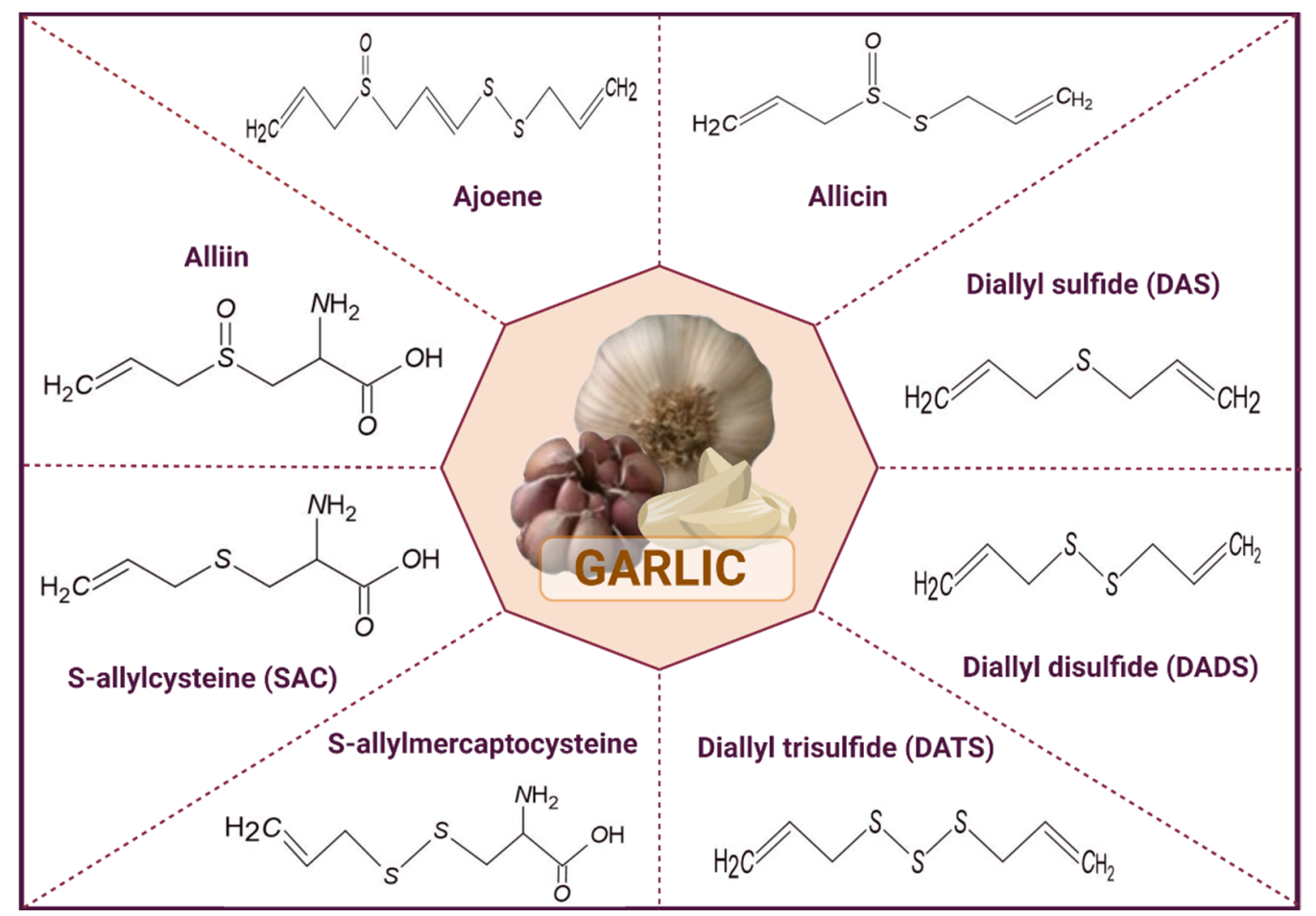

Figure 1. Structures of some of the organosulfur compounds present in garlic.

\section{Antioxidant Activity of Garlic and Garlic Compounds}

It has been demonstrated that natural compounds such as garlic and garlic-derived compounds can upregulate detoxifying enzymes and the enzymes involved in the antioxidant activity, thus decreasing the intracellular ROS [46,47]. The two allyl derivatives of garlic DAS and DADS can modulate the phase II detoxifying enzymes. Thus, it was demonstrated that DADS in high doses increased the activity of quinone reductase $(\mathrm{QR})$ and glutathione S-transferase (GST) in the gastrointestinal tract of rats; therefore, the dose used in this study was close to that achieved through the human consumption of garlic [48]. The effects of garlic oil, DADS, and DAS were demonstrated in rats fed with a high-fat diet; thus, DAS and DADS increased GST activity, whereas DADS only increased 7-pent-oxyresorufin O-dealkylase activity. In addition, DADS and DAS increased the hepatic glutathione reductase (GR) activity; garlic oil, DADS, and DAS increased red blood cell GSH concentration; and, finally, garlic oil improved the superoxide dismutase (SOD) activity [49]. In the induced oral tumour tissue from hamsters treated with aqueous garlic extract, a decrease in lipid peroxidation, followed by a significant increase of reduced glutathione (GSH), glutathione peroxidase (GPx), and GST [50] was observed. AGE exhibited the suppression of $\mathrm{H}_{2} \mathrm{O}_{2}$ and $\mathrm{O}_{2}{ }^{-}$generation in endothelial cells and significantly increased the activities of SOD, catalase, and GPx [51]. In rats with adriamycin-induced cardiotoxicity, the fresh garlic homogenate treatment demonstrated a significant decrease of lipid peroxidation and a significant increase in myocardial catalase, SOD, and GPx [52]. The treatment with allicin to cultured endothelial cells up-regulated phase II detoxifying enzymes, such as heme oxygenase- 1 (HO-1), thioredoxin reductase 1 and 2, and the glutamate-cysteine ligase modifier subunit, which is a limiting enzyme in glutathione biosynthesis, preventing ROS damage [53]. Treatment with AGE significantly increased the antioxidant defence systems, as indicated by increased levels of antioxidant enzymes catalase and SOD and decreased lipid peroxidation in liver and kidney tissues [54]. Alliin reduced the receptor activator of nuclear factor- $\mathrm{kB}$ ligand (RANKL)-induced osteoclastogenesis and decreased the degeneration of ROS and NADPH oxidase 1 [55]. These data suggest that garlic and garlic-derived compounds could be effective as antioxidants and play an important role against oxidative stress. 


\section{Allicin and NB}

Allicin is a sulfur compound produced upon garlic tissue damage by alliin in a reaction catalyzed by the enzyme alliinase [56]. The effects of this compound on some cancers such as osteosarcoma, melanoma, glioblastoma, colon cancer, and liver cancer have been studied [57-63]. However, there are few reports on its use and mechanism of action on NB.

Allicin has been shown to decrease cell viability and the proliferation of human NB cell lines. After $24 \mathrm{~h}$ of exposure to allicin, the induction of poly (ADP-ribose) polymerase (PARP) was observed; this enzyme, among other functions, participates in programmed cell death. Another crtitical effect reported is the inhibition of ornithine decarboxylase, an enzyme that has oncogenic abilities [64], as it causes an increase in polyamines that are linked to the hyperproliferation of neoplastic cells [65]. This inhibiting effect has been reported for the SK-NFI, SK-N-AS, SK-N-Be, and Kelly cell lines treated with allicin concentrations of 12.5 and $25 \mu \mathrm{M}$ [13].

Treatment of the SK-N-SH cell line with $5 \mu \mathrm{mol} / 1$ allicin for $24 \mathrm{~h}$ induced apoptosis by activating the p38 MAPK pathway and the subsequent release of cytochrome c (cyt c) [14].

Another report on the antitumor properties of allicin demonstrated that the combined therapy with allicin $(10 \mathrm{mg} / \mathrm{kg} /$ day $)$ and cyclophosphamide decreased the size of induced tumors in BALB/c-nu/nu mice bearing an SH-SY5Y NB cell line. Following combined therapy, tumor cell proliferation decreased (as assessed by histology) and the survival of the mice bearing the tumors increased. Moreover, the combined therapy (allicin+cyclophosphamide) increased the number of CD4+, CD8+, and NK cells, as well as the IFN- $\gamma$ levels, in the serum. Interestingly, both the mRNA and protein levels of vascular endothelial growth factor (VEGF) decreased [15]. VEGF is a key molecule in the angiogenesis process and has been considered as a therapeutic target in NB [66]. These findings suggest that natural compounds derived from garlic may exhibit a synergistic effect when combined with conventional chemotherapeutic drugs (Figure 2).

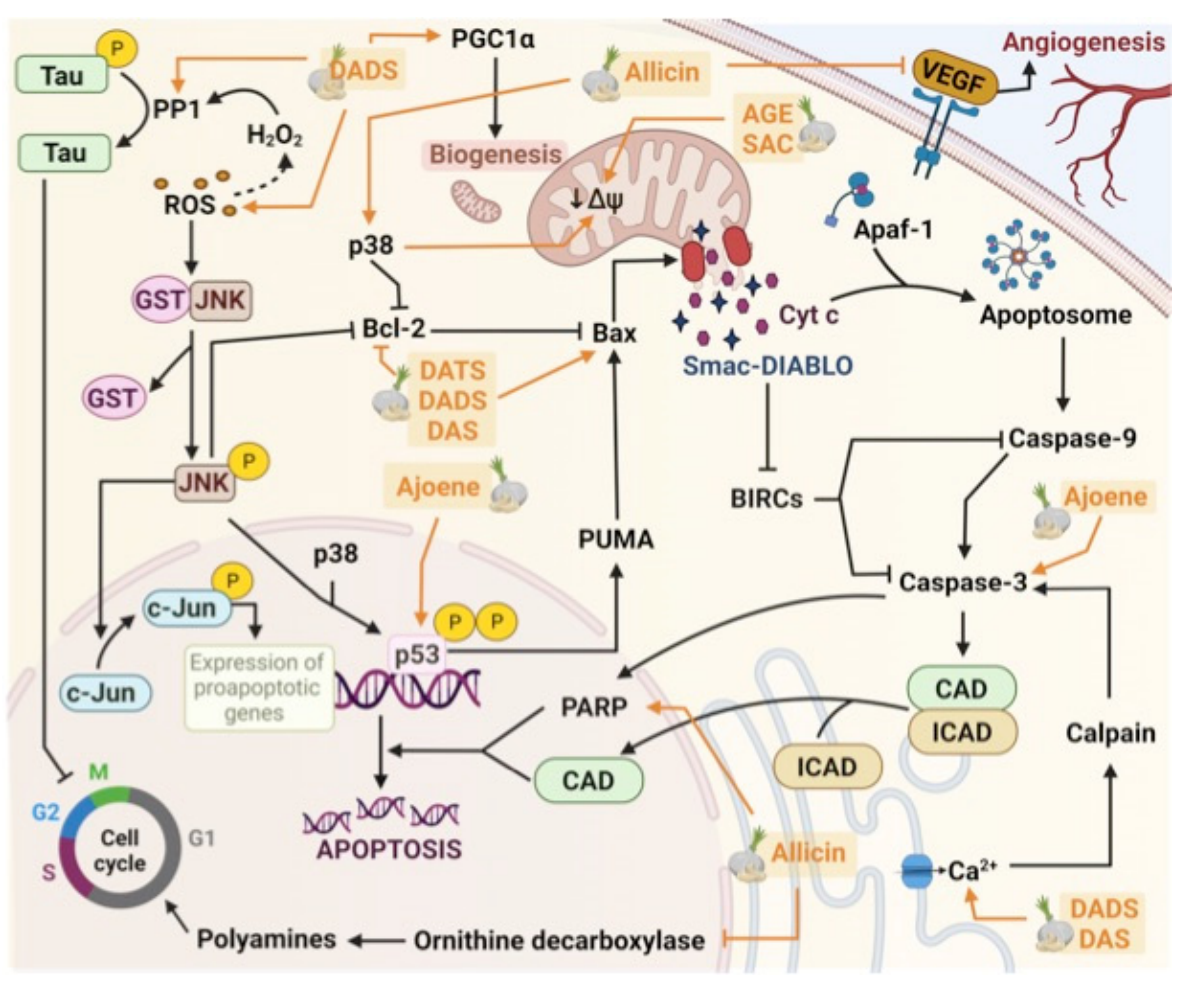

Figure 2. Schematic diagram of the molecular mechanisms of the effects of organosulfur compounds of garlic on the neuroblastoma. 


\section{Ajoene and NB}

Ajoene is a compound derived from allicin, which exists as cis(Z)-ajoene and trans(E)ajoene isomers. The antitumor properties of ajoene have been reported both in vitro and in vivo, but its effects on NB have not been explored much [67]. Only one report has shown the antitumor effect of Z-ajoene on the SK-N-AS cell line through induction of apoptosis, which was evinced by the increase in annexin $V$, propidium iodide, active caspase-3, and p53 $6 \mathrm{~h}$ after the treatment [16]. This report is interesting as it suggests a p53-dependent mechanism of action (Figure 2).

\section{SAC and NB}

As previously mentioned, AGE is one of the most popular presentations of garlic, with SAC being a major component.

Welch et al. used the LA-N-5 human NB cell line to evaluate the antitumor effect of SAC. The cells were treated with SAC at 200, 400, 800, and $1600 \mu \mathrm{g} / \mathrm{mL}$ for 8 days. Decreased cell proliferation was observed from $400 \mu \mathrm{g} / \mathrm{mL}$ of SAC, thus demonstrating the antiproliferative potential of this compound. However, based on the evaluated morphological, biochemical, and molecular markers, the treatment failed to differentiate the NB cells [17].

Another study used the SJ-NK-P and IMR5 cell lines, and showed that SAC affects the mitochondrial membrane potential (Figure 2). The cells were treated with 1 and $2 \mathrm{mg} / \mathrm{mL}$ AGE, and the membrane potential $(\Delta \Psi \mathrm{m})$ and chemical gradient $(\Delta \mathrm{pHm})$, expressed in $\mathrm{mV}$, were evaluated. AGE induced a decrease in $\Delta \Psi \mathrm{m}$ of up to $120 \mathrm{mV}$, and the $58 \Delta \mathrm{pHm}$ value decreased by $10 \mathrm{mV}$. Changes in these parameters were accompanied by increased glutathione oxidation, as evinced by the decreased amount of reduced glutathione. After treatment of the cells with $20 \mathrm{mM} \mathrm{SAC}$ for $48 \mathrm{~h}$, the number of apoptotic cells increased and the cell cycle was arrested at the G1 phase [18].

To date, few studies have been conducted on the use of SAC in cancer models. The available data support the potential use of AGE and SAC in the treatment of this disease.

\section{DAS, DADS, DATS, and NB}

The effects of DAS, DADS, and DATS on NB have been reported; however, the mechanism of action remains unclear.

Filomeni et al. demonstrated that DADS (50 $\mu \mathrm{M}$ for $24 \mathrm{~h})$ induced apoptosis through the downregulation of the mitochondrial pathway (Bcl-2, release of cyt c into the cytosol, and activation of caspase-9) in association with the activation of the JNK/c-Jun pathway in SH-SY5Y cells (Figure 2) [19].

Karkamar et al. observed an increase in the intracellular $\mathrm{Ca}^{2+}$ levels, which triggered cell death due to endoplasmic reticulum stress in SH-SY5Y cells treated with DAS and DADS. The increase in intracellular $\mathrm{Ca}^{2+}$ upregulated the expression of the $\mathrm{Ca}^{2+}$-dependent protease calpain in the cells treated with DAS and DADS (Figure 2). The overexpression of calpain is associated with changes in the Bax/Bcl-2 ratio, which causes cell death through the release of cyt $\mathrm{c}$ from the mitochondria. The Bax/Bcl-2 ratio increased in the SH-SY5Y cells after treatment with DAS and DADS [20].

Aquilano et al. treated SH-SY5Y cells with $50 \mu \mathrm{mol} / \mathrm{L}$ DADS and observed that DADS induced the disruption of the cytoskeleton (Figure 2). The cctin levels decreased significantly $6 \mathrm{~h}$ after the treatment, and significant disruption of the microtubule network along with actin loss was observed by immunofluorescence in DADS-treated cells. These changes in the cytoskeleton could be explained by Tau protein dephosphorylation mediated by the protein phosphatase 1 (PP1) in a ROS-dependent pathway after treatment with DADS [21].

Pagliei et al. described the effects of the peroxisome proliferator-activated receptorgamma co-activator 1 alpha (PGC1 $\alpha$ ) as an anti-apoptotic agent in DADS-treated SH-SY5Y cells ( $50 \mu \mathrm{M}$ for 3,6 , and $9 \mathrm{~h}$ ). DADS promoted the activation of PGC1 $\alpha$ in a time-dependent manner, reaching a maximum expression $9 \mathrm{~h}$ after treatment. The activation of the PGC1 $\alpha$ 
protein favored mitochondrial biogenesis (increase in mitochondrial mass) and reduced the apoptotic effects of DADS. PGC $1 \alpha$ has been linked to both pro- and anti-cancer effects. In prostate, skin, breast, ovarian, liver, and colon cancers, it has been shown to promote mitochondrial biogenesis, thus increasing the size and proliferation of the tumors. These effects are associated with ROS levels and other oxidative stress indicators, which either activate or inhibite PGC1 $\alpha$ and protect the mitochondria from malfunctioning due to oxidative stress. Given the anti-apoptotic response in the treated NB cells, the expression of PGC $1 \alpha$ as an anti- or pro-apoptotic agent would depend on the type of cancer. Specifically, in the NB cells, PGC1 $\alpha$ showed an anti-apoptotic response and decreased the efficacy of treatment with DADS (and possibly with other drugs that promote the death of cancer cells through apoptosis) [22].

Jurkowska et al. treated glioblastoma (U87MG) and NB (SH-SY5Y) cells with DATS. In U87MG cells, exposure to $100 \mu \mathrm{M}$ DATS caused a decrease in Bcl-2 and increased hydrogen sulfide $\left(\mathrm{H}_{2} \mathrm{~S}\right)$ production, which was associated with increased levels of GSH. The production of $\mathrm{H}_{2} \mathrm{~S}$ could be associated with the increased activity of proteins that promote the transfer of sulfur atoms (MPST and rhodanese), forming sulfane sulfur; the latter would be transferred to the cysteine residues of Bcl-2. In NB cells, the Bcl-2 inactivation mechanism could not be associated with the apoptotic effect found in the study due to the low cysteine levels in these cells. However, ROS production could also support this mechanism, which would cause Bcl-2 inactivation through phosphorylation. The most significant antiproliferative activity was observed at $48 \mathrm{~h} \mathrm{[23].}$

Treatment with some garlic compounds can induce apoptosis in tumor cells. Ajoene increases p53 expression, which is phosphorylated $(\mathrm{P})$ and activates the p53 upregulated modulator of apoptosis (PUMA). In the cytoplasm, PUMA activates pro-apoptotic proteins, such as B-cell lymphoma 2 (Bcl-2)-like protein 4 (Bax), which create a pore in the outer mitochondrial membrane and trigger the release of cyt $\mathrm{c}$ and the second mitochondriaderived activator of caspase/direct inhibitor of apoptosis protein (IAP)-binding protein with a low pI (Smac-DIABLO). DAS, DADS, and DATS also increase Bax and decrease Bcl-2, which enhance the effect. p38 activated by allicin also inhibits Bcl-2, and like SAC and AGE, it decreases the mitochondrial membrane potential. Cyt $\mathrm{c}$ in the cytosol induces the oligomerization of apoptotic peptidase activating factor 1 (Apaf-1). Apaf-1, cyt c, and adenosine triphosphate (ATP) form the apoptosome, which activates caspase-9. Activated caspase- 9 leads to the processing of effector caspases, such as caspase-3. Caspase-3 can also be activated by calpain, which is first activated by the increase in free intracellular $\mathrm{Ca}^{2+}$ mediated by DAS and DADS. Smac-DIABLO inhibits survival signals through the downregulation of baculoviral inhibitors of apoptosis repeat containing (BIRC) proteins and allows for the activation of caspase-3. Activated caspase-3 degrades the inhibitor of caspase-activated DNase (ICAD). Free CAD cleaves the DNA into internucleosomal fragments. Caspase-3 also causes the cleavage of PARP, leading to DNA fragmentation and inhibition of the repair mechanisms. Allicin increases PARP levels. Apoptosis could also be induced through the c-Jun $\mathrm{NH}_{2}-\mathrm{N}$-terminal kinase (JNK/c-Jun) pathway. DADS could increase ROS levels; under stress conditions, GST and JNK disassociate, which leads to JNK activation by phosphorylation. Activated JNK leads to c-Jun activation by phosphorylation and the expression of pro-apoptotic genes. Moreover, the increase in ROS, such as hydrogen peroxide $\left(\mathrm{H}_{2} \mathrm{O}_{2}\right)$, could cause Tau dephosphorylation catalyzed by protein phosphatase 1 (PP1). Tau dephosphorylation contributes to cell cycle arrest. The cell cycle can also be inhibited by allicin, which reduces ornithine decarboxylase levels. Allicin also reduces vascular endothelial growth factor (VEGF) levels, which leads to decreased angiogenesis. Finally, DADS also increases the levels of the transcriptional co-activator peroxisome proliferator activated receptor gamma co-activator 1 alpha $(\mathrm{PGC} 1 \alpha)$, a factor that promotes mitochondrial biogenesis. PGC1 $\alpha$ has been linked to both pro- and anti-cancer effects, and the expression of PGC1 $\alpha$ as an anti- or pro-apoptotic agent would depend on the type of cancer. 


\section{Effects of Garlic on Neurodegenerative Diseases}

Several neurodegenerative diseases such as Alzheimer's, Parkinson's, and Huntington's diseases and amyotrophic lateral sclerosis present hallmarks of degenerative processes (e.g., oxidative stress, mitochondrial damage, inflammation, and apoptosis), and treatment with several natural compounds is expected to delay the onset and reduce the symptoms. Thus, in the Alzheimer's mouse model (Tg2576) that overexpressed a mutant form of the amyloid precursor protein, the AGE decreased cerebral plaques and detergent-resistant and soluble $\beta$-amyloid peptide $(\mathrm{A} \beta)$-species, reduced neuroinflammation, and reduced phosphorylation-induced conformational change in tau protein [68]. AGE ameliorated A $\beta$-induced neurotoxicity in PC12 cells by preventing intracellular ROS accumulation. Moreover, AGE also improved learning and memory deficits in ICV A $\beta$ injected mice [69]. Treatment with AGE in rats injected with $A \beta$ significantly improved the working memory and significantly ameliorated the loss of cholinergic neurons, and increased the vesicular glutamate transporter 1 and glutamate decarboxylase levels in the hippocampus [70]. Pre-treatment of AGE ameliorated the cognitive dysfunction in $\mathrm{A} \beta$-induced neurotoxicity rats and increased the activities of SOD and GPx, and reduced the lipid peroxidation levels in rat brain homogenates [71]. 1-Methyl-4-phenylpyridinium $\left(\mathrm{MPP}^{+}\right)$caused nigrostriatal dopaminergic neurotoxicity, and it is widely used as a model of Parkinson's disease. Thus, SAC protected against the oxidative stress induced by $\mathrm{MPP}^{+}$in the mouse striatum, by improved hyperlocomotion, decreased lipid peroxidation and ROS production, and increased SOD1 activity. [72]. Garlic extract protected the dopaminergic neurons in 6-hydroxydopamine (6-OHDA) injected rats (which is used as a model for Parkinson's disease) by improving 6-OHDA-induced motor dysfunctions and alleviating non-motor deficits, including memory impairment and anxiety in rats [73]. In rat brain synaptosomes, SAC, which is a compound in AGE, decreased lipid peroxidation and mitochondrial dysfunction induced by 3-nitropropionic acid, which produces oxidative and nitrosative stress and evokes an experimental model of Huntington's disease. [74]. Moreover, SAC was used in an animal model of Huntington's disease, and SAC treatment increased SOD1 and 2, and decreased lipid peroxidation and mitochondrial dysfunction and prevented behavioural alterations [75]. The effects of DATS, a major constituent in garlic oil, were evaluated in a transgenic mouse model of amyotrophic lateral sclerosis. DATS treatment in SOD1-G93A transgenic mice induced HO-1 and reduced glial fibrillary acidic protein (GFAP) expression in the lumbar spinal cord [76]. This data suggest the possible roles of garlic and garlic-derived compounds as antioxidant agents, and it is also suggested that they can act as a neuroprotector in several neurodegenerative diseases. Nevertheless, further studies are warranted to verify the effects, dosages, and efficacy of garlic, either alone or in combination with other garlic-derived compounds, as a possible treatment alternative for neurodegenerative diseases.

\section{Conclusions}

Garlic has been shown to have therapeutic properties in the treatment of several neurodegenerative diseases, including cancer. The molecular mechanisms through which garlic exerts its antioxidative and antitumor effects have not been fully described and depend not only on the type of compound, but also on the type of cancer to be treated. NB is a childhood tumor of public health importance; therefore, it is imperative to find new therapeutic alternatives that are affordable and do not affect the patients' quality of life. Although reports are scarce, garlic-derived compounds have shown antioxidative and antitumor effects on NB-derived cells, which make them good candidates to be used as adjuvants in treatment. However, further studies using animal models and patient trials are needed.

Given the lack of information to date, the exploration of garlic-derived compounds as adjuvants in the treatment of NB opens the door to future studies that could help clarify the molecular mechanisms of action. 
Author Contributions: C.C.P.-M., M.S.-G., R.J.-C., C.S.-G. and J.C.C. conceived and wrote the manuscript. C.C.P.-M., E.Y.H.-C., R.J.-C. and M.S.-G. created the figures and tables. C.C.P.-M., C.S.-G., J.P.-C., P.D.M., I.K.-J. and C.A.S.-I. prepared the manuscript. C.C.P.-M., M.S.-G. and C.S.-G. edited the manuscript. All authors have read and agreed to the published version of the manuscript.

Funding: This work was supported by Fondos Federales HIM/2021/033.

Conflicts of Interest: The authors declare no conflict of interest.

\section{References}

1. Maris, J.M. Recent Advances in Neuroblastoma. N. Engl. J. Med. 2010, 362, 2202-2211. [CrossRef]

2. PDQ Pediatric Treatment Editorial Board. Neuroblastoma Treatment $\left(\mathrm{PDQ}^{\circledR}\right)$ : Health Professional Version. In PDQ Cancer Information Summaries; Bethesda: Rockville, MD, USA; National Cancer Institute: Rockville, MD, USA, 2002.

3. London, W.B.; Castleberry, R.P.; Matthay, K.K.; Look, A.; Seeger, R.C.; Shimada, H.; Thorner, P.S.; Brodeur, G.M.; Maris, J.M.; Reynolds, C.P.; et al. Evidence for an Age Cutoff Greater Than 365 Days for Neuroblastoma Risk Group Stratification in the Children's Oncology Group. J. Clin. Oncol. 2005, 23, 6459-6465. [CrossRef]

4. Zafar, A.; Wang, W.; Liu, G.; Wang, X.; Xian, W.; McKeon, F.; Foster, J.; Zhou, J.; Zhang, R. Molecular targeting therapies for neuroblastoma: Progress and challenges. Med. Res. Rev. 2020, 41, 961-1021. [CrossRef]

5. Cohn, S.L.; Pearson, A.D.J.; London, W.B.; Monclair, T.; Ambros, P.F.; Brodeur, G.M.; Faldum, A.; Hero, B.; Iehara, T.; Machin, D.; et al. The international neuroblastoma risk group (INRG) classification system: An INRG task force report. J. Clin. Oncol. 2009, 27, 289-297. [CrossRef] [PubMed]

6. Kholodenko, I.V.; Kalinovsky, D.V.; Doronin, I.I.; Deyev, S.M.; Kholodenko, R.V. Neuroblastoma Origin and Therapeutic Targets for Immunotherapy. J. Immunol. Res. 2018, 2018, 1-25. [CrossRef] [PubMed]

7. Twist, C.J.; Schmidt, M.L.; Naranjo, A.; London, W.B.; Tenney, S.C.; Marachelian, A.; Shimada, H.; Collins, M.H.; Esiashvili, N.; Adkins, E.S.; et al. Maintaining Outstanding Outcomes Using Response- and Biology-Based Therapy for Intermediate-Risk Neuroblastoma: A Report from the Children's Oncology Group Study ANBL0531. J. Clin. Oncol. 2019, 37, 3243-3255. [CrossRef] [PubMed]

8. Tolbert, V.P.; Matthay, K.K. Neuroblastoma: Clinical and biological approach to risk stratification and treatment. Cell Tissue Res. 2018, 372, 195-209. [CrossRef]

9. Berlanga, P.; Cañete, A.; Castel, V. Advances in emerging drugs for the treatment of neuroblastoma. Expert Opin. Emerg. Drugs 2016, 22, 63-75. [CrossRef] [PubMed]

10. Matthay, K.K.; Reynolds, C.P.; Seeger, R.C.; Shimada, H.; Adkins, E.S.; Haas-Kogan, D.; Gerbing, R.B.; London, W.B.; Villablanca, J.G. Long-Term Results for Children with High-Risk Neuroblastoma Treated on a Randomized Trial of Myeloablative Therapy Followed by 13-cis-Retinoic Acid: A Children's Oncology Group Study. J. Clin. Oncol. 2009, 27, 1007-1013. [CrossRef] [PubMed]

11. Castel, V.; Cañete, A.; Navarro, S.; García-Miguel, P.; Melero, C.; Acha, T.; Navajas, A.; Badal, M. Outcome of high-risk neuroblastoma using a dose intensity approach: Improvement in initial but not in long-term results. Med. Pediatr. Oncol. 2001, 37, 537-542. [CrossRef] [PubMed]

12. Luksch, R.; Castellani, M.R.; Collini, P.; De Bernardi, B.; Conte, M.; Gambini, C.; Gandola, L.; Garaventa, A.; Biasoni, D.; Podda, M.; et al. Neuroblastoma (Peripheral neuroblastic tumours). Crit. Rev. Oncol. 2016, 107, 163-181. [CrossRef]

13. Schultz, C.R.; Gruhlke, M.C.H.; Slusarenko, A.J.; Bachmann, A.S. Allicin, a Potent New Ornithine Decarboxylase Inhibitor in Neuroblastoma Cells. J. Nat. Prod. 2020, 83, 2518-2527. [CrossRef]

14. Zhuang, J.; Li, Y.; Chi, Y. Role of p38 MAPK activation and mitochondrial cytochrome-c release in allicin-induced apoptosis in SK-N-SH cells. Anti-Cancer Drugs 2016, 27, 312-317. [CrossRef]

15. Gao, X.-Y.; Geng, X.-J.; Zhai, W.-L.; Zhang, X.-W.; Wei, Y.; Hou, G.-J. Effect of combined treatment with cyclophosphamidum and allicin on neuroblastoma-bearing mice. Asian Pac. J. Trop. Med. 2015, 8, 137-141. [CrossRef]

16. Terrasson, J.; Xu, B.; Li, M.; Allart, S.; Davignon, J.-L.; Zhang, L.-H.; Wang, K.; Davrinche, C. Activities of Z-ajoene against tumour and viral spreading in vitro. Fundam. Clin. Pharmacol. 2007, 21, 281-289. [CrossRef] [PubMed]

17. Welch, C.; Wuarin, L.; Sidell, N. Antiproliferative effect of the garlic compound S-allyl cysteine on human neuroblastoma cells in vitro. Cancer Lett. 1992, 63, 211-219. [CrossRef]

18. Kanamori, Y.; Via, L.D.; Macone, A.; Canettieri, G.; Greco, A.; Toninello, A.; Agostinelli, E. Aged garlic extract and its constituent, S-allyl-L-cysteine, induce the apoptosis of neuroblastoma cancer cells due to mitochondrial membrane depolarization. Exp. Ther. Med. 2019, 19, 1511-1521. [CrossRef]

19. Filomeni, G.; Aquilano, K.; Rotilio, G.; Ciriolo, M.R. Reactive oxygen species-dependent c-Jun NH2-terminal kinase/c-Jun signaling cascade mediates neuroblastoma cell death induced by diallyl disulfide. Cancer Res. 2003, 63, 5940-5949. [PubMed]

20. Karmakar, S.; Banik, N.L.; Patel, S.J.; Ray, S.K. Garlic compounds induced calpain and intrinsic caspase cascade for apoptosis in human malignant neuroblastoma SH-SY5Y cells. Apoptosis 2007, 12, 671-684. [CrossRef]

21. Aquilano, K.; Vigilanza, P.; Filomeni, G.; Rotilio, G.; Ciriolo, M.R. Tau dephosphorylation and microfilaments disruption are upstream events of the anti-proliferative effects of dads in sh-sy5y cells. J. Cell. Mol. Med. 2008, 14, 564-577. [CrossRef]

22. Pagliei, B.; Aquilano, K.; Baldelli, S.; Ciriolo, M.R. Garlic-derived diallyl disulfide modulates peroxisome proliferator activated receptor gamma co-activator 1 alpha in neuroblastoma cells. Biochem. Pharmacol. 2013, 85, 335-344. [CrossRef] 
23. Jurkowska, H.; Wróbel, M.; Kaczor-Kamińska, M.; Jasek-Gajda, E. A possible mechanism of inhibition of U87MG and SH-SY5Y cancer cell proliferation by diallyl trisulfide and other aspects of its activity. Amino Acids 2017, 49, 1855-1866. [CrossRef] [PubMed]

24. White, D. Healthy Uses for Garlic. Nurs. Clin. N. Am. 2021, 56, 153-156. [CrossRef]

25. Moyers, S. Garlic in Health, History and World Cuisine; Suncoast Press: St Petersburg, FL, USA, 1996; pp. 1-36.

26. Woodward, P.W. Garlic and Friends: The History, Growth and Use of Edible Alliums; Hyland House: Melbourne, Australia, 1996; pp. 2-22.

27. Gebhardt, R.; Beck, H.; Wagner, K.G. Inhibition of cholesterol biosynthesis by allicin and ajoene in rat hepatocytes and HepG2 cells. Biochim. Biophys. Acta (BBA) Lipids Lipid Metab. 1994, 1213, 57-62. [CrossRef]

28. Eilat, S.; Oestraicher, Y.; Rabinkov, A.; Ohad, D.; Mirelman, D.; Battler, A.; Eldar, M.; Vered, Z. Alteration of lipid profile in hyperlipidemic rabbits by allicin, an active constituent of garlic. Coron. Arter. Dis. 1995, 6, 985-990.

29. Shadkchan, Y.; Shemesh, E.; Mirelman, D.; Miron, T.; Rabinkov, A.; Wilchek, M.; Osherov, N. Efficacy of allicin, the reactive molecule of garlic, in inhibiting Aspergillus spp. in vitro, and in a murine model of disseminated aspergillosis. J. Antimicrob. Chemother. 2004, 53, 832-836. [CrossRef] [PubMed]

30. Benavides, G.A.; Squadrito, G.L.; Mills, R.W.; Patel, H.D.; Isbell, T.S.; Patel, R.P.; Darley-Usmar, V.M.; Doeller, J.E.; Kraus, D.W. Hydrogen sulfide mediates the vasoactivity of garlic. Proc. Natl. Acad. Sci. USA 2007, 104, 17977-17982. [CrossRef]

31. Zoccali, C.; Catalano, C.; Rastelli, S. Blood pressure control: Hydrogen sulfide, a new gasotransmitter, takes stage. Nephrol. Dial. Transplant. 2009, 24, 1394-1396. [CrossRef]

32. Zhang, Y.; Liu, X.; Ruan, J.; Zhuang, X.; Zhang, X.; Li, Z. Phytochemicals of garlic: Promising candidates for cancer therapy. Biomed. Pharmacother. 2019, 123, 109730. [CrossRef] [PubMed]

33. Cheng, H.; Huang, G.; Huang, H. The antioxidant activities of garlic polysaccharide and its derivatives. Int. J. Biol. Macromol. 2019, 145, 819-826. [CrossRef]

34. Furhad, S.; Bokhari, A.A. Herbal Supplements; StatPearls Publishing: St. Petersburg, FL, USA, 2021.

35. Varshney, R.; Budoff, M.J. Garlic and Heart Disease. J. Nutr. 2016, 146, 416S-421S. [CrossRef]

36. Mathew, B.; Biju, R. Neuroprotective Effects of Garlic: A Review. Libyan J. Med. 2008, 3, 23-33. [CrossRef] [PubMed]

37. Lawson, L.D. Garlic: A review of its medicinal effects and indicated active compounds. Phytomedicines of Europe. Chem. Biol. Act. 1998, 691, 176-209.

38. Iberl, B.; Winkler, G.; Müller, B.; Knobloch, K. Quantitative Determination of Allicin and Alliin from Garlic by HPLC. Planta Med. 1990, 56, 320-326. [CrossRef]

39. Iberl, B.; Winkler, G.; Knobloch, K. Products of Allicin Transformation: Ajoenes and Dithiins, Characterization and their Determination by HPLC. Planta Med. 1990, 56, 202-211. [CrossRef]

40. Lawson, L.D.; Hughes, B.G. Characterization of the formation of allicin and other thiosulfinates from garlic. Planta Med. 1992, 58, 345-350. [CrossRef]

41. Borek, C. Antioxidant Health Effects of Aged Garlic Extract. J. Nutr. 2001, 131, 1010S-1015S. [CrossRef]

42. Czepukojc, B.; Baltes, A.-K.; Cerella, C.; Kelkel, M.; Viswanathan, U.M.; Salm, F.; Burkholz, T.; Schneider, C.; Dicato, M.; Montenarh, M.; et al. Synthetic polysulfane derivatives induce cell cycle arrest and apoptotic cell death in human hematopoietic cancer cells. Food Chem. Toxicol. 2014, 64, 249-257. [CrossRef]

43. Nicastro, H.L.; Ross, S.A.; Milner, J.A. Garlic and Onions: Their Cancer Prevention Properties. Cancer Prev. Res. 2015, 8, 181-189. [CrossRef]

44. Steinmetz, K.A.; Kushi, L.H.; Bostick, R.M.; Folsom, A.R.; Potter, J.D. Vegetables, Fruit, and Colon Cancer in the lowa Women's Health Study. Am. J. Epidemiol. 1994, 139, 1-15. [CrossRef]

45. Dorant, E.; Brandt, P.V.D.; Goldbohm, R.; Hermus, R.; Sturmans, F. Garlic and its significance for the prevention of cancer in humans: A critical view. Br. J. Cancer 1993, 67, 424-429. [CrossRef]

46. Trio, P.Z.; You, S.; He, X.; He, J.; Sakao, K.; Hou, D.-X. Chemopreventive functions and molecular mechanisms of garlic organosulfur compounds. Food Funct. 2014, 5, 833-844. [CrossRef]

47. Farhat, Z.; Hershberger, P.A.; Freudenheim, J.L.; Mammen, M.J.; Blair, R.H.; Aga, D.S.; Mu, L. Types of garlic and their anticancer and antioxidant activity: A review of the epidemiologic and experimental evidence. Eur. J. Nutr. 2021, 60, 3585-3609. [CrossRef]

48. Munday, R.; Munday, C.M. Low Doses of Diallyl Disulfide, a Compound Derived from Garlic, Increase Tissue Activities of Quinone Reductase and Glutathione Transferase in the Gastrointestinal Tract of the Rat. Nutr. Cancer 1999, 34, 42-48. [CrossRef]

49. Sheen, L.-Y.; Chen, H.-W.; Kung, Y.-L.; Liu, C.-T.; Lii, C.-K. Effects of Garlic Oil and Its Organosulfur Compounds on the Activities of Hepatic Drug-Metabolizing and Antioxidant Enzymes in Rats Fed High- and Low-Fat Diets. Nutr. Cancer 1999, 35, 160-166. [CrossRef]

50. Balasenthil, S.; Arivazhagan, S.; Ramachandran, C.R.; Nagini, S. Effects of garlic on 7,12-Dimethylbenz[a]anthracene-induced hamster buccal pouch carcinogenesis. Cancer Detect. Prev. 1999, 23, 534-538. [CrossRef]

51. Wei, Z.; Lau, B.H. Garlic inhibits free radical generation and augments antioxidant enzyme activity in vascular endothelial cells. Nutr. Res. 1998, 18, 61-70. [CrossRef]

52. Mukherjee, S.; Banerjee, S.K.; Maulik, M.; Dinda, A.K.; Talwar, K.K.; Maulik, S.K. Protection against acute adriamycin-induced cardiotoxicity by garlic: Role of endogenous antioxidants and inhibition of TNF- $\alpha$ expression. BMC Pharmacol. $2003,3,16$. [CrossRef] 
53. Horev-Azaria, L.; Eliav, S.; Izigov, N.; Pri-Chen, S.; Mirelman, D.; Miron, T.; Rabinkov, A.; Wilchek, M.; Jacob-Hirsch, J.; Amariglio, N.; et al. Allicin up-regulates cellular glutathione level in vascular endothelial cells. Eur. J. Nutr. 2008, 48, 67-74. [CrossRef]

54. Thomson, M.; Al-Qattan, K.K.; Js, D.; Ali, M. Anti-diabetic and anti-oxidant potential of aged garlic extract (AGE) in streptozotocininduced diabetic rats. BMC Complement. Altern. Med. 2015, 16, 17. [CrossRef]

55. Chen, Y.; Sun, J.; Dou, C.; Li, N.; Kang, F.; Wang, Y.; Cao, Z.; Yang, X.; Dong, S. Alliin Attenuated RANKL-Induced Osteoclastogenesis by Scavenging Reactive Oxygen Species through Inhibiting Nox1. Int. J. Mol. Sci. 2016, 17, 1516. [CrossRef]

56. Borlinghaus, J.; Albrecht, F.; Gruhlke, M.C.H.; Nwachukwu, I.; Slusarenko, A.J. Allicin: Chemistry and Biological Properties. Molecules 2014, 19, 12591-12618. [CrossRef]

57. Gruhlke, M.C.H.; Slusarenko, A.J. The Chemistry of Alliums. Molecules 2018, 23, 143. [CrossRef] [PubMed]

58. Bat-Chen, W.; Golan, T.; Peri, I.; Ludmer, Z.; Schwartz, B. Allicin Purified from Fresh Garlic Cloves Induces Apoptosis in Colon Cancer Cells Via Nrf2. Nutr. Cancer 2010, 62, 947-957. [CrossRef] [PubMed]

59. Chen, H.; Zhu, B.; Zhao, L.; Liu, Y.; Zhao, F.; Feng, J.; Jin, Y.; Sun, J.; Geng, R.; Wei, Y. Allicin Inhibits Proliferation and Invasion in Vitro and in Vivo via SHP-1-Mediated STAT3 Signaling in Cholangiocarcinoma. Cell. Physiol. Biochem. 2018, 47, 641-653. [CrossRef]

60. Li, X.; Ni, J.; Tang, Y.; Wang, X.; Tang, H.; Li, H.; Zhang, S.; Shen, X. Allicin inhibits mouse colorectal tumorigenesis through suppressing the activation of STAT3 signaling pathway. Nat. Prod. Res. 2018, 33, 2722-2725. [CrossRef] [PubMed]

61. Zou, X.; Liang, J.; Sun, J.; Hu, X.; Lei, L.; Wu, D.; Liu, L. Allicin sensitizes hepatocellular cancer cells to anti-tumor activity of 5-fluorouracil through ROS-mediated mitochondrial pathway. J. Pharmacol. Sci. 2016, 131, 233-240. [CrossRef]

62. Jiang, W.; Huang, Y.; Wang, J.-P.; Yu, X.-Y.; Zhang, L.-Y. The synergistic anticancer effect of Artesunate COMBINED with allicin in osteosarcoma cell line in vitro and in vivo. Asian Pac. J. Cancer Prev. 2013, 14, 4615-4619. [CrossRef]

63. Jobani, B.M.; Najafzadeh, N.; Mazani, M.; Arzanlou, M.; Vardin, M.M. Molecular mechanism and cytotoxicity of allicin and all-trans retinoic acid against CD44+ versus CD117+ melanoma cells. Phytomedicine 2018, 48, 161-169. [CrossRef]

64. Auvinen, M.; Paasinen, A.; Andersson, L.C.; Hölttä, E. Ornithine decarboxylase activity is critical for cell transformation. Nature 1992, 360, 355-358. [CrossRef]

65. Bachmann, A.S.; Geerts, D. Polyamine synthesis as a target of MYC oncogenes. J. Biol. Chem. 2018, 293, 18757-18769. [CrossRef]

66. Ribatti, D. Anti-angiogenesis in neuroblastoma. Crit. Rev. Oncol. 2013, 86, 212-221. [CrossRef] [PubMed]

67. Li, M.; Ciu, J.-R.; Ye, Y.; Min, J.-M.; Zhang, L.-H.; Wang, K.; Gares, M.; Cros, J.; Wright, M.; Leung-Tack, J. Antitumor activity of Z-ajoene, a natural compound purified from garlic: Antimitotic and microtubule-interaction properties. Carcinogenesis 2002, 23, 573-579. [CrossRef]

68. Chauhan, N.B. Effect of aged garlic extract on APP processing and tau phosphorylation in Alzheimer's transgenic model Tg2576. J. Ethnopharmacol. 2006, 108, 385-394. [CrossRef]

69. Jeong, J.H.; Jeong, H.R.; Na Jo, Y.; Kim, H.J.; Shin, J.H.; Heo, H.J. Ameliorating effects of aged garlic extracts against A $\beta$-induced neurotoxicity and cognitive impairment. BMC Complement. Altern. Med. 2013, 13, 268. [CrossRef]

70. Thorajak, P.; Pannangrong, W.; Welbat, J.U.; Chaijaroonkhanarak, W.; Sripanidkulchai, K.; Sripanidkulchai, B. Effects of Aged Garlic Extract on Cholinergic, Glutamatergic and GABAergic Systems with Regard to Cognitive Impairment in A $\beta$-Induced Rats. Nutrients 2017, 9, 686. [CrossRef] [PubMed]

71. Pannangrong, W.; Welbat, J.U.; Chaichun, A.; Sripanidkulchai, B. Effect of combined extracts of aged garlic, ginger, and chili peppers on cognitive performance and brain antioxidant markers in A $\beta$-induced rats. Exp. Anim. 2020, 69, 269-278. [CrossRef]

72. Rojas, P.; Serrano-García, N.; Medina-Campos, O.N.; Pedraza-Chaverri, J.; Maldonado, P.D.; Ruiz-Sánchez, E. S-Allylcysteine, a garlic compound, protects against oxidative stress in 1-methyl-4-phenylpyridinium-induced parkinsonism in mice. J. Nutr. Biochem. 2011, 22, 937-944. [CrossRef]

73. Bigham, M.; Mohammadipour, A.; Hosseini, M.; Malvandi, A.M.; Ebrahimzadeh-Bideskan, A. Neuroprotective effects of garlic extract on dopaminergic neurons of substantia nigra in a rat model of Parkinson's disease: Motor and non-motor outcomes. Metab. Brain Dis. 2021, 36, 927-937. [CrossRef] [PubMed]

74. La Cruz, V.P.-D.; González-Cortés, C.; Pedraza-Chaverri, J.; Maldonado, P.D.; Andrés-Martínez, L.; Santamaría, A. Protective effect of S-allylcysteine on 3-nitropropionic acid-induced lipid peroxidation and mitochondrial dysfunction in rat brain synaptosomes. Brain Res. Bull. 2006, 68, 379-383. [CrossRef]

75. Herrera-Mundo, M.N.; Adaya, I.D.S.; Maldonado, P.D.; Galván-Arzate, S.; Andrés-Martínez, L.; La Cruz, V.P.-D.; PedrazaChaverrí, J.; Santamaría, A. S-Allylcysteine prevents the rat from 3-nitropropionic acid-induced hyperactivity, early markers of oxidative stress and mitochondrial dysfunction. Neurosci. Res. 2006, 56, 39-44. [CrossRef]

76. Guo, Y.; Zhang, K.; Wang, Q.; Li, Z.; Yin, Y.; Xu, Q.; Duan, W.; Li, C. Neuroprotective effects of diallyl trisulfide in SOD1-G93A transgenic mouse model of amyotrophic lateral sclerosis. Brain Res. 2011, 1374, 110-115. [CrossRef] 